\title{
A sweet potato story: the likelihood of porina feeding on kumara
}

H. Ehau-Taumaunu ${ }^{1,2}$, S.D.G. Marshall', C.M. Ferguson ${ }^{3}$, M. Mark-Shadbolt², R.M. MacDiarmid ${ }^{4}$ and M. O'Callaghan ${ }^{1}$

${ }^{1}$ AgResearch, Private Bag 4749, Christchurch 8140, New Zealand

${ }^{2}$ Bio-Protection Research Centre, Lincoln University, Canterbury 7647, New Zealand

${ }^{3}$ AgResearch, Invermay Agricultural Centre, Private Bag 50034, Mosgiel 9053, New Zealand

${ }^{4}$ Plant \& Food Research, Private Bag 92169, Auckland 1142, New Zealand

Corresponding author: hanareia.ehau-taumaunu@agresearch.co.nz

The caterpillar stage of the endemic Wiseana spp. complex, commonly known as porina, are foliage feeders. Research indicates that porina will feed on harakeke (Phormium tenax), red tussock (Chionochloa rubra) and hard tussock (Festuca novae zealandiae). In 1952, Miller reported that porina were abundant in kumara plantations and caused damage to the plants. The accuracy of this observation is uncertain due to taxonomic changes and the ambiguous nature of Miller's identification. Feeding bioassays were undertaken to determine if porina caterpillars would feed on the leaves, stems, or tuber of the Owairaka kumara plant (Ipomoea batatas) using white clover foliage (Trifolium repens) as a control. Over a 6-week incubation period, at a constant temperature of $15^{\circ} \mathrm{C}$, porina weight increased on all food sources. Porina provided with tuber had a weight increase of $>0.1 \mathrm{~g}$ within the first two weeks, which was a $122 \%$ gain (compared to clover). The leaves and stems supported less weight gain over the two week period ( $92 \%$ and $85 \%$ compared to clover, respectively). These results suggest that porina can feed on kumara plants, but further field testing will be required to support this claim.

\section{Monitoring the concentration of methyl bromide in the treated space during commercial fumigation of logs}

\author{
M.K.D. Hall, A.R. Adlam, A.J. Hall and A.J. Najar-Rodriguez
}

Plant \& Food Fesearch, Palmerston North 4474, New Zealand

Corresponding author: matthew.hall@plantandfood.co.nz

Development of science-based fumigation schedules for phytosanitary treatments relies on an understanding of the factors which influence the effectiveness of a fumigant under different conditions. Understanding the sorption characteristics of a fumigant is a critical step in establishing commercial treatment schedules, as this process, which involves adsorption and absorption of fumigant molecules, influences the concentration of the fumigant remaining in the treated space after fumigation and hence the amount of fumigant available to kill insects. We monitored the concentration of methyl bromide during commercial fumigation of three log stacks (average volume $=407.8 \mathrm{~m}^{3}$ ) with $120 \mathrm{~g} / \mathrm{m}^{3}$ methyl bromide for $13 \mathrm{~h}$ under a tarpaulin. Pine (Pinus radiata D. Don.) logs were fumigated at South Port, Bluff (New Zealand) during April 2015. Gas samples from the treated space were taken at 0.5, 1, 2, 3, 4,9 and $13 \mathrm{~h}$ after fumigation. After $13 \mathrm{~h}, 44 \pm 6 \%$ of the initial concentration of fumigant remained in the treated space, indicating that the rest of the fumigant was sorbed. These data can now be combined with insect toxicity studies to guide the development of improved commercial treatment schedules to treat log exports from New Zealand. 